\title{
Weekly High-dose 5-Fluorouracil as 24-hour Infusion Combined with Sodium Folinic Acid (AIO regimen) Plus Irinotecan in Second-line and Sequential Therapy of Metastatic Colorectal Cancer (CRC)
}

\author{
AXEL WEIN $^{1}$, JUERGEN SIEBLER $^{1}$, KERSTIN WOLFF $^{1}$, NICOLA OSTERMEIER $^{1}$, \\ DAGMAR BUSSE ${ }^{1}$, ALEXANDER HAGEL $^{1}$, FRANZ KOCH $^{1}$, \\ KIRSTEN MERX ${ }^{2}$, MARKUS FRIEDRICH NEURATH ${ }^{1}$ and RALF-DIETER HOFHEINZ ${ }^{2}$ \\ ${ }^{1}$ Department of Internal Medicine 1, Gastroenterology, Pneumology, and Endocrinology, \\ Friedrich-Alexander-University, Erlangen-Nuremberg, Germany; \\ ${ }^{2}$ Department of Internal Medicine 3, Internal Medicine, Oncology, Hematology, \\ Mannheim University, Mannheim, Germany
}

\begin{abstract}
Background/Aim: The aim of this work was to evaluate the efficacy and safety of second-line treatment with weekly high-dose 5-fluorouracil (5-FU) as a 24-hour infusion (24-h inf.) combined with sodium folinic acid (FA) (AIOregimen) plus irinotecan (Iri.) after pretreatment with $\mathrm{AIO}$ regimen plus oxaliplatin $(\mathrm{L}-\mathrm{OHP})$. Patients and Methods: Patients with non-resectable distant CRC metastases were enrolled in a prospective phase II study for palliative secondline treatment after previous progression of first-line treatment in accordance with the AIO-regimen plus oxaliplatin. On an outpatient basis, the patients received a treatment regimen comprising of weekly $80 \mathrm{mg} / \mathrm{m}^{2}$ irinotecan in the form of a 1-hour i.v. infusion and 2,000 $\mathrm{mg} / \mathrm{m}^{2} 5-F U$ combined with $500 \mathrm{mg} / \mathrm{m}^{2}$ sodium folinic acid administered as a 24-h infusion i.v. once weekly. Results: During secondline treatment, a total of 59 patients received 520 chemotherapy applications. As the main higher-grade symptom of toxicity, diarrhea (NCI-CTC-toxicity grade 3) presented in 8 patients $(13.6 \%, 95 \% C I=5.1-23.7)$, followed by leukocytopenia (CTC grade 3) in 3 patients $(5.1 \%$, 95\%CI=0-11.9), followed by thrombocytopenia (CTC grade $3)$ in 1 patient $(1.7 \%, 95 \% C I=0-5.1)$. Fifty-nine patients were
\end{abstract}

Correspondence to: Prof. Dr. med. Axel Wein, Department of Internal Medicine 1, Gastroenterology, Pulmonology, and Endocrinology Friedrich-Alexander University, Ulmenweg 18, 91054 Erlangen, Germany. Tel: +49 91318535060, Fax: +49 91318535062,e-mail: axel.wein@uk-erlangen.de

Key Words: Colorectal cancer, second-line AIO plus irinotecan, palliative sequential therapy. evaluable for treatment response. The remission data can be summarized as follows: complete remission $(C R) ; n=0$; partial remission $(P R) ; n=6(10 \% ; 95 \% C I=3.4-18.6) ;$ stable disease $(S D) ; n=31$ (53\%; 95\%CI=39.0-64.4); progressive disease $(P D) ; n=19$ (33\%; 95\%CI=20.3-44.1). The median progression-free survival $(P F S)$ rate $(n=59)$ was 4.2 months (range=3.8-5.8 months). The median survival time counted from the start of second-line treatment $(n=59) 14.2$ months (range 8.2-17.3 months) and the median survival time counted from the start of first-line therapy $(n=59) 25$ months (range 19-27 months). Conclusion: Palliative second-line treatment according to the AIO regimen plus irinotecan offers both a favourable toxicity profile and promising efficacy in second-line and palliative sequential therapy.

Colorectal cancer (CRC) is the second most common form of cancer in women and the third most common cancer in men. In 2008, the estimated worldwide incidence of CRC exceeded 1.2 million, with over 600,000 deaths per year (1). In Germany, CRC is one of the most common malignancies, with more than 70,000 new cases and approximately 30,000 deaths recorded annually (2). Metastasis at diagnosis is seen in about $20-25 \%$ of all patients with CRC (2).

Irinotecan has proven antineoplastic activity in first- and second-line treatment of CRC in clinical studies, both as monotherapy and in combination with 5-fluorouracil (5-FU) (3-15). In two randomized phase III studies, irinotecan monotherapy was investigated as a second-line treatment in patients with metastasized colorectal carcinoma pretreated with 5-FU $(3,4)$.

In a phase III study $(\mathrm{n}=267)$, second-line treatment with irinotecan monotherapy was compared to various 5-FU 
infusion regimens ("De Gramont", "Lokich", "AIO") in patients pretreated with bolus 5-FU. The 12-months survival rate was significantly improved with irinotecan as secondline treatment, i.e., 45 versus $32 \%$. Likewise, median and progression-free (OS and PFS) were significantly better (OS: 10.8 versus 8.5 months, $p=0.035$. Progression-free survival (PFS) was also significantly improved by irinotecan chemotherapy (4.2 vs. 2.9 months; $p=0.030$ ) (3). Another phase III study $(n=279)$ compared irinotecan monotherapy versus best support of care as second-line treatment in CRC patients pretreated with 5-FU demonstrated. Expectedly, even greater improvements were reported: the 1-year survival rate 36.2 versus $13.8 \%$, and median survival time was 9.2 versus 6.5 months $(p=0.0001)$ (4). Based on these results, irinotecan monotherapy was for a while considered the standard second-line treatment for CRC patients pretreated with 5-FU (2). In another phase III study $(n=291)$ it was possible to show that in CRC patients pretreated with 5-FU, triweekly application of irinotecan monotherapy (with $350 \mathrm{mg} / \mathrm{m}^{2} i . v$.) was similarly effective to weekly application (with $125 \mathrm{mg} / \mathrm{m}^{2} i . v$.), but with an improved toxicity profile (5). In a small randomized phase II study, it could be shown that in patients with metastasized CRC and 5-FU pretreatment, the AIO regimen plus irinotecan was equally efficient to irinotecan monotherapy $\left(350 \mathrm{mg} / \mathrm{m}^{2}\right.$, triweekly) as second-line treatment and also elicited a more favorable toxicity profile (6).

In the age of combined chemotherapy, studies preferentially applied the biweekly FOLFIRI regimen (calcium folinate, 5FU, and irinotecan) as second-line treatment after pretreatment with oxaliplatin-based combined chemotherapy (7-10). On the other hand, weekly regimens, such as the AIO regimen plus irinotecan, for example, are widely used and effective as firstline treatment in particular (11-13).

Prior to the present study, the authors initially retrospectively analyzed patients of a test cohort who received AIO plus irinotecan as second- and third-line treatment, after progression following first-line treatment with AIO plus oxaliplatin (L-OHP) (14). Subsequently, in order to validate these retrospective data, the current prospective phase II study of AIO plus irinotecan as secondline treatment was performed in a homogenous patient cohort after progression following palliative first-line treatment with L-OHP (15).

This phase II study was conducted in the treatment era prior to targeted therapy. The FOLFIRI regimen followed by FOLFOX6 regimen (calcium folinate, 5-FU, and oxaliplatin) (or vice versa) was considered the gold standard of sequential CRC treatment in the non-biological era (7). The widespread weekly administration of chemotherapy (e.g., AIO regimen plus irinotecan in first-line treatment (11-13)) has not yet been investigated for second-line treatment after pretreatment with oxaliplatin-based combined chemotherapy.

\section{Patients and Methods}

Patients. The study protocol of our second-line treatment was approved by the local ethics committee of the two German centers and met the standards laid down in the Helsinki Declaration of 1975 (in its current, revised form). Prior to enrollment, written informed consent was obtained from every patient. This bi-centric phase II study included only patients with histologically confirmed colorectal cancer after progression of first-line therapy with AIO regimen plus oxaliplatin. The patients revealed distant metastases measuring at least $2 \mathrm{~cm}$ in diameter and were definitively non-resectable. Inclusion criteria were an ECOG index $\leq 2$, age $\geq 18$ and $\leq 75$ years, adequate bone narrow function, leukocytes $\geq 3,500 / \mu 1$, platelets $\geq 100,000 / \mu$ l, adequate liver function (serum bilirubin $\leq$ at least $2 x$ upper reference range) and renal function (creatinine $\leq 1.5 \mathrm{x}$ the upper reference range).

Exclusion criteria were relevant cardiac disease, CNS metastasis or another malignancy capable of reducing life expectancy, with the exception of cutaneous basal cell carcinoma and intra-epithelial carcinoma of the cervix.

Before initiating treatment, a medical history, physical examination, laboratory investigations, a CT scan of the abdomen and chest, and, where relevant complaints presented, further imaging procedures such as bone scan or CT scan of the head were obtained.

Prior to first-line treatment a port-a-cath was surgically implanted via the cephalic vein.

Treatment protocol. On an outpatient basis, the patients received a treatment regimen comprising weekly $80 \mathrm{mg} / \mathrm{m}^{2}$ irinotecan in the form of a $1 \mathrm{~h}$-infusion and $2,000 \mathrm{mg} / \mathrm{m}^{2} 5$-FU combined with $500 \mathrm{mg} / \mathrm{m}^{2}$ sodium folinic acid administered as a $24 \mathrm{~h}$-infusion $i . v$. via a miniature pump system applied on days 1, 8, 15, 22, 29 and 36 once weekly. This procedure was repeated on day 57 . A treatment cycle comprised 6 weekly infusions by 2 weeks of rest. Treatment was continued until tumor progression, unexpected toxicity, or necessary measures, such as surgical intervention with secondary metastatic resection. As prophylactic antiemetic, ondansetron $\left(\operatorname{Zofran}^{\circledR}\right)$ : $8 \mathrm{mg}$ i.v. and Dexamethasone (Fortecortin ${ }^{\circledR}$ ): $8 \mathrm{mg}$ i.v. was given. Two hundred and fifty $\mu \mathrm{g}$ of atropine was applied subcutaneously to avoid cholinergic symptoms before initiating treatment with irinotecan.

Prior to each weekly application, the NCI-CTC toxicity was determined and the blood was checked. In the case of diarrhea (CTC grade $\geq 2$ ) the patient was instructed to take $2 \mathrm{mg}$ loperamid (Immodium ${ }^{\circledR}$ ) after every bowel, up to $8 \times 2 \mathrm{mg}$ p.os/d. according to predefined guideline recommendations. If this medication failed to improve the diarrhea within $24 \mathrm{~h}$ the patient was hospitalized for rehydration and medication. After every cycle ( 8 weeks), follow-up examination comprising a blood count, screening test for CEA and CA19-9, an abdominal and chest CT scan was performed.

Methods. The treatment response was checked for all CT images by an experienced radiologist. Computed tomography was repeated every eight weeks or earlier if clinical deterioration was observed. Anti-tumor activity was evaluated in accordance with RECIST criteria (16). In order to be categorized as partial remission (PR) or complete remission (CR), the confirmatory $\mathrm{CT}$ was required at least 4 weeks after the initial imaging (16). The treatment toxicity was evaluated in accordance with the National Cancer Institute Common Toxicity Criteria (NCI-CTC), version 2.0 (17). If, prior to 
chemotherapy a NCI-CTC toxicity $\geq$ grade 2 was present, treatment was delayed by 1 week (exception: alopecia) or more until a toxicity grade $\leq 1$ was achieved. In the event of NCI-CTC toxicity grade 3 or 4 during the treated-free interval, the 5-FU and irinotecan dose for the next application was reduced to $75 \%$ of the planned dose. If the toxicity grade 3 or 4 presented again, the 5-FU and irinotecan dose had to be reduced to $50 \%$ of the planned dose.

Statistical consideration. The primary endpoint of the bi-centric phase II study was progression free survival (PFS). Secondary endpoints were the median survival time of the second-line therapy and median survival time of first- and second-line therapy (sequential therapy), the objective response rate (ORR) and the NCI-CTC toxicity grades of second-line treatment.

The hypothesis was that the median survival of second-line treatment with irinotecan combined therapy was longer than with irinotecan monotherapy. The same relationship was assumed for the time until tumor progression (PFS). With a ratio of median survivaltime under irinotecan containing combined chemotherapy (7) to median survival time with irinotecan monotherapy (3) of $9.2 / 10.2=0.90$ it can be shown that in a collective of 50 patients, with a probability of making a type I error of $\alpha=0.05$ and a probability of a type II error of $\beta=0.20$ (power $=80 \%$ ), the median survival under irinotecan-containing combined chemotherapy is longer than with irinotecan monotherapy (one sided tests, control sample exact test) (18). The actual power of PFS is, however, somewhat lower since some patients will be lost before the endpoint is reached. Therefore, the study intended to recruit 60 patients.

Both, OS and PFS, were analyzed by the Kaplan-Meier-method. PFS was defined as the time from start of second-line therapy to first radiological or clinical observation of disease progression, or death from any cause. All variables were summarized by descriptive statistics. The $99 \%$ confidence intervals (CIs) were calculated to the Greenwood Criteria (19). All analyses were performed using the statistics software SPSS for Windows Version 10 (SPSS Inc., Chicago, USA).

\section{Results}

Between May 2002 and June 2010, a total of 60 patients were recruited into this phase II study from two German centers. The data from a total of 59 patients were evaluated. The cutoff date was November 30, 2012. At that time, all patients had terminated second-line treatment. Median follow-up was 11 months (range=8-15). Additional patient data are depicted in Table I.

Toxicity and drug administration of second-line treatment. The symptoms of toxicity experienced by the 59 patients are listed in Table II. Therapy-related gastrointestinal side effects, in particular severe diarrhea (CTC grade 3+4) predominated and was seen in 8 patients (13.6\%; $95 \% \mathrm{CI}=5.1-23.7)$. Severe hematological toxicity (CTC grade $3+4)$ was rare. 3 patients experienced a higher grade leukocytopenia $(5.1 \% ; 95 \% \mathrm{CI}=0-11.9)$ and one patient a higher grade (CTC grade 3+4) thrombocytopenia (1.7\%; $95 \% \mathrm{CI}=0-5.1)$. Stationary treatment due to higher grade
Table I. Patient characteristics $(n=59)$.

\begin{tabular}{lc}
\hline $\begin{array}{l}\text { Median age (years); (range) } \\
\text { Location of primary tumor }\end{array}$ & $65 ;(37-75)$ \\
$\quad$ Rectum & $\mathrm{n}=27(45 \%)$ \\
$\quad$ Colon & $\mathrm{n}=32(55 \%)$ \\
Resection of primary tumor & $\mathrm{n}=59(100 \%)$ \\
Gender & \\
$\quad$ Male & $\mathrm{n}=42(72 \%)$ \\
Female & $\mathrm{n}=17(28 \%)$ \\
ECOG score & \\
0 & $\mathrm{n}=34(57 \%)$ \\
1 & $\mathrm{n}=23(39 \%)$ \\
2 & $\mathrm{n}=2(4 \%)$ \\
Number of metastatic sites & \\
1 & $\mathrm{n}=27(46 \%)$ \\
$\geq 2$ & $\mathrm{n}=32(54 \%)$ \\
Liver-only metastasis & \\
Yes & $\mathrm{n}=19(32 \%)$ \\
No & $\mathrm{n}=40(68 \%)$ \\
Secondary metastatic resection & $\mathrm{n}=1(1.7 \%)$ \\
\hline
\end{tabular}

toxicity did not prove necessary, although 2 patients had to be hospitalized due to tumor-related complaints such a paralytic ileus and severe aszites. No treatment-related deaths occurred.

A total of 520 chemotherapy applications (90 cycles) were administered. One full cycle of AIO plus irinotecan was received by $33 \%$ of patients, $17 \%$ received two cycles, $22 \%$ three, $12 \%$ four, $7 \%$ five, and $2 \%$ of patients received six cycles. An overview of the toxicity experienced per patient is given in Table II. Higher-grade hematological side effects (toxicity grades 3 and 4 ) occurred in 3 patients $(5.1 \%$; 95\% CI=0-11.9) in the form of leukocytopenia; other highgrade toxicities manifested as gastrointestinal tract toxicity: 8 patients $(13.6 \% ; 95 \% \mathrm{CI}=5.1-23.7)$ with diarrhea and 2 (3.4\%; 95\%CI=0.0-10.2) with vomiting (see Table II).

Response rate, median progression-free survival. One patient who had signed the informed consent form did not present at the study center (drop-out) and was thus not eligible for toxicity and efficacy analysis. PR was observed in 6 patients $(10 \%$; 95\% CI=3.4-18.6), 31 patients $(53 \%$; 95\%CI=39.064.4) could be registered as having SD, and 19 patients (33\%; 95\% CI=20.3-44.1) had PD. Median PFS was 4.2 months (range=3.8-5.8 months; Figure 1).

PFS and median survival time of second-line treatment and of sequence therapy. By the last follow-up assessment, 59 patients (100\%) had died. Median OS calculated from the start of second-line therapy $(n=59)$ was 14.2 months (range=8.2-17.3 months; see Figure 2). The median overall survival of first- and second-line chemotherapy was 25 months (range $=19-27$ 
Table II. Maximum toxicity per patient $(n=59)$ and item during palliative second-line treatment with AIO plus irinotecan

\begin{tabular}{|c|c|c|c|c|c|}
\hline \multirow[b]{2}{*}{ Toxicity } & \multicolumn{5}{|c|}{ NCI-CTC grade (n (\%)) } \\
\hline & Grade 0 & Grade 1 & Grade 2 & Grade 3 & Grade 4 \\
\hline Anemia, n (\%) & $53(89.8)$ & $4(6.8)$ & $2(3.4)$ & - & - \\
\hline Leukocytopenia, n (\%) & $37(62.7)$ & $10(17.0)$ & $9(15.2)$ & $3(5.1)$ & - \\
\hline Thrombocytopenia, n (\%) & $56(94.9)$ & $1(1.7)$ & $1(1.7)$ & $1(1.7)$ & - \\
\hline Stomatitis, $\mathrm{n}(\%)$ & $55(93.2)$ & $3(5.1)$ & $1(1.7)$ & - & - \\
\hline Nausea, n (\%) & $24(40.7)$ & $31(52.5)$ & $4(6.8)$ & - & - \\
\hline Vomiting, n (\%) & $42(71.2)$ & $11(18.6)$ & $4(6.8)$ & $1(1.7)$ & $1(1.7)$ \\
\hline Diarrhea, n (\%) & $14(23.7)$ & $22(37.3)$ & $15(25.4)$ & $8(13.6)$ & - \\
\hline Hand-foot syndrome, n (\%) & $53(89.8)$ & $5(8.5)$ & $1(1.7)$ & - & - \\
\hline Alopecia, n (\%) & $56(94.9)$ & $2(3.4)$ & $1(1.7)$ & - & - \\
\hline
\end{tabular}

NCI-CTC: National cancer institute common toxicity criteria.

months). Third-line treatment after tumor progression of second-line was received by 21 patients $(36 \% ; 95 \% \mathrm{CI}=22.3$ 46.5), most frequently a cetuximab/irinotecan combination.

\section{Discussion}

In the treatment era prior to targeted therapy, the FOLFOX6 schedule followed by FOLFIRI (or vice versa) was considered the gold standard of sequential treatment in CRC (7). In the French phase III study by GERCOR ("Groupe Coopérateur Multidisciplinaire en Oncologie"), the biweekly infusion regimens in the therapeutic sequences FOLFOX6 followed by FOLFIRI and FOLFIRI followed by FOLFOX6 were able to achieve survival times of over 22 months in both treatment arms (7). In a meta-analysis of 11 published phase III studies comprising a total of 5,768 patients with metastasized colorectal carcinoma, multivariate analysis demonstrated that the decisive factor for OS in palliative sequential therapy was that all available substances (5FU/folinic acid/oxaliplatin and irinotecan) were applied in the therapeutic sequence of first- and second-line treatment, and not whether first-line therapy was begun with 5-FU monotherapy or combined chemotherapy $(20,21)$.

In a healthcare research study conducted in Germany (2004-2011), median survival times of 22 months were also reached in palliative patients with metastasized colorectal carcinoma in the sequential therapy, although in this study, biologicals were sometimes also incorporated in the treatment sequence (22). In the current phase II study the therapeutic sequence of AIO plus oxaliplatin followed by AIO plus irinotecan achieved a median survival of 25 months (range=19-27 months); the median OS of second-line therapy with AIO plus irinotecan being 14.2 months (range=8.2-17.3 months) (see Figure 2) (15). With first- and second-line use of bevacizumab ("bevacizumab beyond progression") in the so-called TML phase II study, it was possible to achieve a median OS of 23.9 months with this sequence compared to 22.5 months without biological in second-line treatment $(p=0.17)$ (23). With 11.2 versus 9.8 months, the median OS for second-line therapy was significantly more favorable in this study $(p=0.0062)$, such that second-line bevacizumab was approved for bevacizumab beyond progression (23).

Sequential therapy has become more diverse in recent years. Biologicals have gained a firm place in sequential regimens (23) and new substances - such as aflibercept, an antiangiogenic fusion protein, and ramucirumab, an antiangiogenic antibody-have been approved for use in second-line treatment with FOLFIRI after pretreatment with oxaliplatin-based combined chemotherapy $(8,9)$. Additionally, panitumumab, an epidermal growth factor receptor (EGFR) antagonist, was approved for use in combination with FOLFIRI as second-line treatment in patients with wildtype K-RAS pretreated with oxaliplatin-based combined chemotherapy (10). FOLFIRI has been used as the reference regimen for second-line treatment in various licensing studies (8-10). However, particularly in terms of its toxicity spectrum, the FOLFIRI regimen for first- and second-line treatment has disadvantages compared to the weekly AIO regimen plus irinotecan (see Table III). With FOLFIRI, grade 2 alopecia (complete, reversible hair loss) is observed in $22 \%$ of cases and grade $3 / 4$ neutropenia in $24 \%$ of patients (7). With the weekly AIO plus irinotecan regimen as first-line treatment, the rate of grade 2 alopecia was 5\% among the patients and that of grade $3 / 4$ neutropenia $4.8 \%$ (11).

The favorable toxicity aspects of AIO plus irinotecan compared to FOLFIRI are achieved with comparable efficacy data of the two therapeutic regimens in second-line treatment. With FOLFIRI, the efficacy data for second-line treatment in patients pretreated with oxaliplatin-based combined 


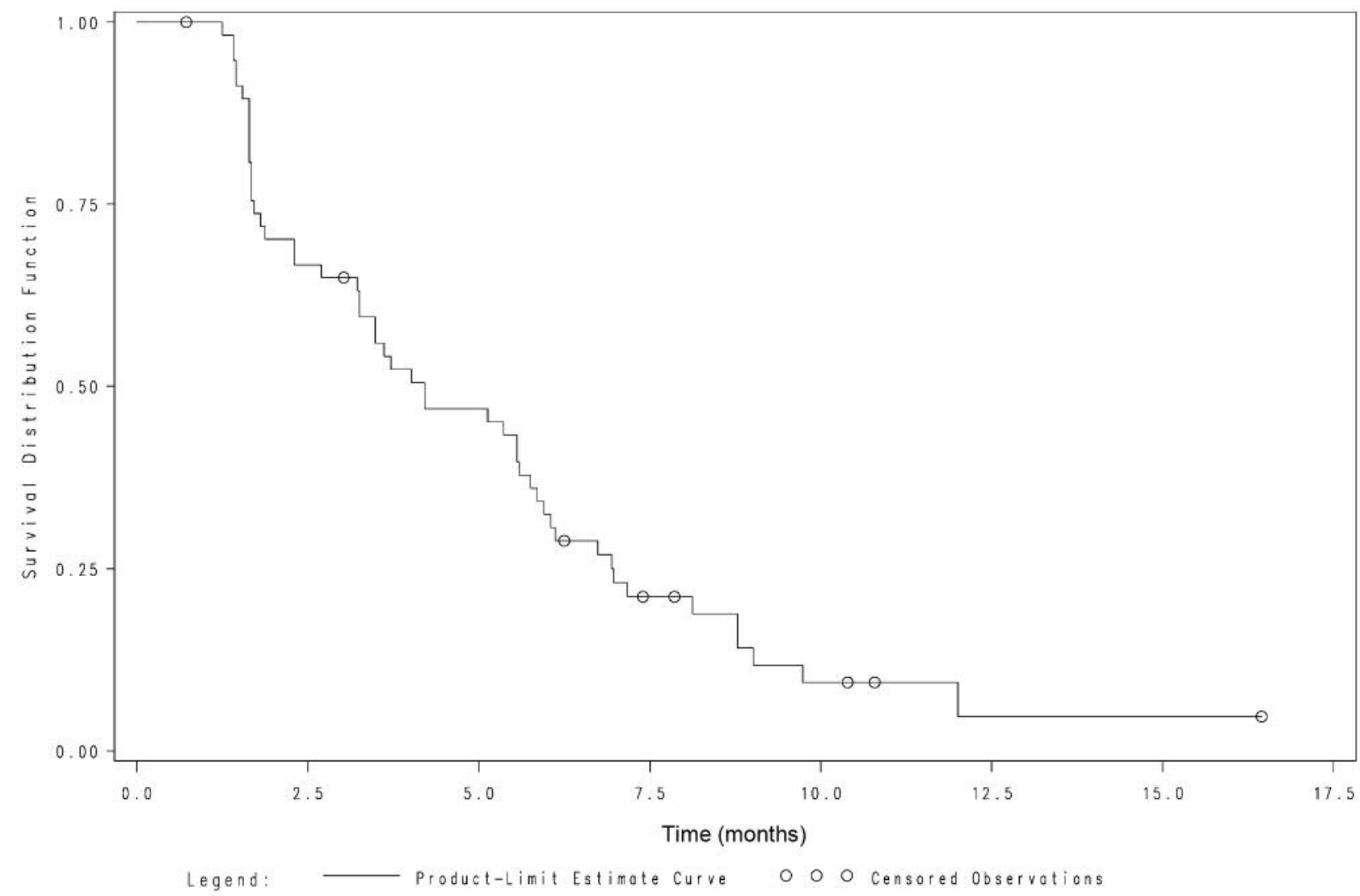

Figure 1. Kaplan-Meier curve for progression-free survival (PFS) from start of second-line therapy (n=59). Median PFS: 4.2 months (range: 3.8 5.8 months). Circles indicate censored data.

chemotherapy lie within following ranges: response rate $(\mathrm{CR}+\mathrm{PR})=4-16.7 \%, \mathrm{PFS}=2.5-5.1$ months, OS=9.3-18.2 months (see Table III) $(7,8,24)$. The study with the best efficacy data exhibited heterogeneous pretreatments (5-FU monotherapy in 40\%, oxaliplatin-based combined chemotherapy in 60\%) and originated in Asia (Table III) (24). With the AIO plus irinotecan regimen in second-line treatment, the response data $(\mathrm{CR}+\mathrm{PR})$ vary between 11 and $27 \%$, depending on the study; PFS is between 3.7 and 5.8 months; and OS varies between 9.5 and 14.2 months (Table III) $(6,14,15)$. The best efficacy data came from a retrospective study (14). In many studies on second-line therapy after pretreatment with oxaliplatin-based combined chemotherapy, a third-line treatment since approval of cetuximab and panitumumab was standard $(10,27)$.

In the era of combined chemotherapy, antiangiogenic biologicals such as bevacizumab, aflibercept (a fusion protein), and ramucirumab (an antibody), for example, have recently been approved for phase III studies of second-line treatment following oxaliplatin-based combined chemotherapy $(8,9,23)$. In each of these studies, an oxaliplatin-based combined chemotherapy regimen plus/minus biological was applied as first-line treatment and in second-line therapy, FOLFIRI plus/minus one of the aforementioned agents was tested $(8,9,23)$. The most homogenous first-line pretreatment with FOLFOX4 plus bevacizumab is represented by the RAISE study (9). It can be assumed that the less intensive the first-line treatment is, the better the efficacy data of the second-line treatment will be. One example of this is represented by the phase III study by Muro et al. (24): patients pretreated only with 5-FU (40\%) achieved a median PFS in second-line treatment with FOLFIRI of 7.8 months; whereas patients with oxaliplatin-based pretreatment had a median PFS of 3.9 months in second-line treatment (24).

Despite licensing of new drugs, the efficacy data for second-line treatment are still unsatisfactory (see Table III). OS of second-line treatment in the TML study with bevacizumab was only 11.1 months. Although clinically only slightly more favorable, this represented a statistically significant increase compared to the 9.8 months achieved with combined chemotherapy alone (23). In the VELOUR study with FOLFIRI plus aflibercept, the OS of 13.3 months 


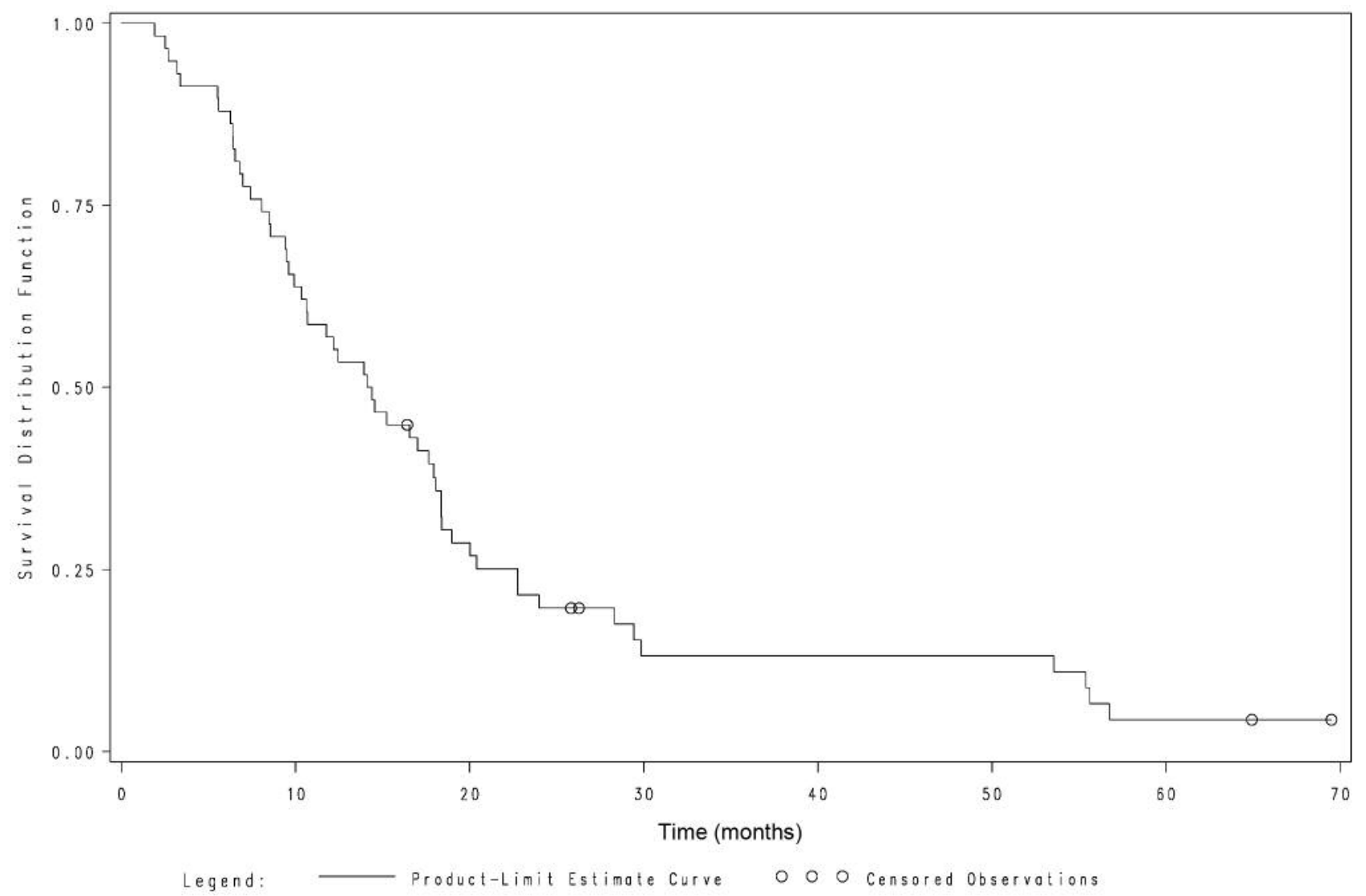

Figure 2. Kaplan-Meier curve for observed overall survival (OS) from start of second-line therapy (n=59). Median survival time: 14.2 months (range: 8.2-17.3 months). Circles indicate censored data.

was clearly better than the OS of 11.7 months achieved by FOLFIRI combined chemotherapy (8) (Table III). Likewise, OS improved significantly with ramucirumab plus FOLFIRI, from 11.7 to 13.5 months (9).

On a critical note, it should be mentioned that in two large phase III pivotal studies, focus was placed on the efficacy of second-line treatment only, and information on OS regarding the sequence of the applied first- and second-line treatments is lacking $(8,9)$. Only the TML study presents data on this (23). Using the sequence of combined chemotherapy plus bevacizumab followed by second-line combined chemotherapy plus bevacizumab, a median OS of 23.9 months was achieved in this phase III study, which represented only a slight clinical advantage over the sequence comprising combined chemotherapy alone $(22.5$ months) (23).

The toxicity profile of the newly-approved substances must also be considered. The combination of aflibercept plus FOLFIRI elicited high-grade neutropenia (grade 3/4) in $36.7 \%$ and high-grade diarrhea (grade $3 / 4$ ) in $83.4 \%$ of patients (8) (Table III). Second-line therapy in CRC is thus still in need of optimization, despite the availability of new therapeutic agents.

As described previously, in patients receiving second-line therapy with liver-only metastases secondary potentially curative metastasis resection after downsizing of palliative second-line therapy may be possible (25). Not only did secondary curative metastasis resection achieve a good survival time of 24 months from the start of second-line treatment, it also afforded this patient a curative option, since he is currently free of recurrence (25). This interdisciplinary multimodal aspect during second-line treatment is promising in general and should be more intensively researched in future prospective studies (26), particularly in light of the fact that many patients still have a liver-only situation at the time of second-line treatment $(8,9)$, which, after downsizing, constitutes a favorable starting point for secondary metastasis resection.

The data from the present study and others on second-line treatment must be critically discussed regarding the selection of prognostic factors. While many studies present no 
Wein et al: Second-line Treatment of AIO Plus Irinotecan in Palliative Therapy of Coloretal Carcinoma

Table III. Efficacy and toxicity of palliative second-line treatment with irinotecan-containing combined chemotherapy following first-line treatment with an oxaliplatin-based combined chemotherapy regimen.

\begin{tabular}{|c|c|c|c|c|c|c|c|c|c|}
\hline Author & $\begin{array}{l}\text { Oxaliplatin- } \\
\text { based } \\
\text { pretreatment }\end{array}$ & $\begin{array}{l}\text { Second-line } \\
\text { regimen }\end{array}$ & Patients & Phase & Response & PFS & OS & $\begin{array}{l}\text { High-grade } \\
\text { toxicity } \\
\text { (grade 3/4) }\end{array}$ & $\begin{array}{c}\text { Consecutive } \\
\text { treatment }\end{array}$ \\
\hline $\begin{array}{l}\text { Stickel et al.; } \\
2003 \text { (14) }\end{array}$ & $\begin{array}{c}\mathrm{AIO}+ \\
\text { oxalinplatin }\end{array}$ & $\begin{array}{c}\mathrm{AIO}+ \\
\text { irinotecan }\end{array}$ & $\mathrm{n}=26$ & Retrospective & $27 \%$ & 5.0 months & 10 months & Diarrhea $19 \%$ & n.i. \\
\hline $\begin{array}{l}\text { Tournigand et al.; } \\
2004 \text { (7) }\end{array}$ & FOLFOX6 & FOLFIRI & $\mathrm{n}=69$ & III & $4 \%$ & 2.5 months & 9.2 months & $\begin{array}{c}\text { Diarrhea } 8 \% \\
\text { Neutropenia } 21 \%\end{array}$ & n.i. \\
\hline $\begin{array}{l}\text { Bidard et al.; } \\
2009 \text { (28) }\end{array}$ & $\begin{array}{l}\text { FOLFOX4 or } \\
\text { FOLFOX7 }\end{array}$ & FOLFIRI & $\mathrm{n}=112$ & III & $8 \%$ & 3.0 months & 9.3 months & n.i. & n.i. \\
\hline $\begin{array}{l}\text { Peeters } \text { et al.; } \\
2014 \text { (10) }\end{array}$ & $\begin{array}{l}\text { FOLFOX }(65 \%) \\
\text { or } 5 \text {-FU/folinic } \\
\text { acid }(35 \%)\end{array}$ & FOLFIRI & $\mathrm{n}=595$ & III & $10 \%$ & 3.9 months & 12.5 months & $\begin{array}{c}\text { Neutropenia } \\
23 \% \\
\text { Diarrhea 9\% }\end{array}$ & n.i. \\
\hline $\begin{array}{l}\text { Wein A et al.; } \\
2013 \text { (15) }\end{array}$ & $\begin{array}{c}\mathrm{AIO}+ \\
\text { oxalinplatin }\end{array}$ & $\begin{array}{c}\mathrm{AIO}+ \\
\text { irinotecan }\end{array}$ & $\mathrm{n}=60$ & II & $10 \%$ & 4.2 months & 14.2 months & $\begin{array}{c}\text { Diarrhea } 13.5 \% \\
\text { Leukocytopenia } 5.1 \%\end{array}$ & yes, $36 \%$ \\
\hline $\begin{array}{l}\text { Van Cutsem } \\
\text { et al.; } 2012 \text { (8) }\end{array}$ & $\begin{array}{l}\text { FOLFOX6 or } \\
\text { FOLFOX4 }\end{array}$ & FOLFIRI & $\mathrm{n}=614$ & III & $11.1 \%$ & 4.67 months & 12.06 months & $\begin{array}{c}\text { Neutropenia } 29.5 \% \\
\text { Diarrhea } 7.8 \%\end{array}$ & yes, $59.5 \%$ \\
\hline $\begin{array}{l}\text { Van Cutsem } \\
\text { et al.; } 2012 \text { (8) }\end{array}$ & $\begin{array}{c}\text { FOLFOX6 or } \\
\text { FOLFOX4 }(70 \%) \\
\text { FOLFOX4 }+ \\
\text { oevacizumab }(30 \%)\end{array}$ & $\begin{array}{l}\text { FOLFIRI + } \\
\text { aflipercept } \\
\text { 6) }\end{array}$ & $\mathrm{n}=612$ & III & $19.8 \%$ & 6.9 months & 13.5 months & $\begin{array}{c}\text { Neutropenia } 36.7 \% \\
\text { Diarrhea } 83.4 \%\end{array}$ & yes, $59.6 \%$ \\
\hline $\begin{array}{l}\text { Tabernero et al.; } \\
2015 \text { (9) }\end{array}$ & $\begin{array}{c}\text { FOLFOX4 + } \\
\text { bevacizumab } \\
(100 \%)\end{array}$ & $\begin{array}{c}\text { FOLFIRI + } \\
\text { ramucirumab }\end{array}$ & $\mathrm{n}=536$ & III & $13.4 \%$ & 5.7 months & 13.3 months & $\begin{array}{c}\text { Neutropenia } 38 \% \\
\text { Diarrhea } 11 \%\end{array}$ & n.i. \\
\hline $\begin{array}{l}\text { Tabernero et al.; } \\
2015 \text { (9) }\end{array}$ & $\begin{array}{c}\text { FOLFOX4 + } \\
\text { bevacizumab } \\
(100 \%)\end{array}$ & $\begin{array}{l}\text { FOLFIRI + } \\
\text { placebo }\end{array}$ & $\mathrm{n}=536$ & III & $12.5 \%$ & 4.5 months & 11.7 months & $\begin{array}{c}\text { Neutropenia } 24 \% \\
\text { Diarrhea } 9 \%\end{array}$ & n.i. \\
\hline $\begin{array}{l}\text { Muro et al.; } \\
2010 \text { (24) }\end{array}$ & $\begin{array}{c}\text { FOLFOX }(60 \%) \\
5 \text {-FU/folinic } \\
\text { acid }(40 \%)\end{array}$ & FOLFIRI & $\mathrm{n}=213$ & III & $16.7 \%$ & 5.1 months & 13.7 months & $\begin{array}{c}\text { Neutropenia } 52.1 \% \\
\text { Diarrhea } 4.7 \% \\
\text { Alopecia } 5.2 \%\end{array}$ & n.i. \\
\hline
\end{tabular}

n.i: No information; PFS:progression-free survival; OS:overall survival; 5-FU:5-fluorouracil.

information regarding further treatments (e.g., third-line therapy) that could possibly have an influence on OS (Table III), $36 \%$ of patients in the current phase II study received consecutive treatment after second-line therapy, preferentially anti-EGFR in the case of wildtype K-RAS (27). This might be one of the factors explaining the more favorable OS of 14.2 months in the current study compared to the 9.2 months achieved with FOLFIRI in the study by Tournigand et al. (7). Only one trial, namely the VELOUR study, has an even higher proportion of patients receiving consecutive treatment, with $59.5 \%$ and $59.6 \%$ in the different treatment arms (8). With 13.5 months, the median OS in the latter study was within the upper range of the survival times reported by the studies on second-line treatment (8) (Table III).

The present phase II study began with inclusion of patients for second-line treatment (15). Patients with an unfavorable prognostic course during first-line therapy $-e . g$., who died early due to high-grade toxicity or rapid progression, which includes approximately $3.7 \%$ of first-line patients with metastasized CRC (29) - cannot be recruited into studies commencing with inclusion of patients into second-line treatment. Consequentially, these results in recruitment and selection of patients with a favorable prognostic course for second-line treatment. How patient selection from first- to second-line treatment looks in terms of percent values is best illustrated by the phase III study by Tournigand et al. (7): during randomization, 111 patients received first-line FOLFOX6 until progression; subsequently, only 69 patients could be treated with second-line FOLFIRI, such that 42 patients $(38 \%)$ in this study did not achieve the objective of second-line treatment (7). This considerable degree of selection must be borne in mind when interpreting the results of second-line treatments in new studies.

\section{Acknowledgements}

The Authors would like to thank IMEREM/RPS Clinical Research, Nuremberg, Germany, for monitoring; Mrs. Carola Scheuerer for preparing the manuscript; Mrs. Gudrun Männlein and Dr. F. Boxberger for their study support; and Mr. F. Dunkl and Mr. K. Mach for statistical assistance. 
This study was partially supported by grants from Pfizer Pharma $\mathrm{GmbH}$, Berlin, Germany, and Medac GmbH, Wedel, Germany.

\section{References}

1 Ferlay J, Shin HR, Bray F, Forman D, Mathers C and Parkin DM: Estimates of worldwide burden of cancer in 2008: GLOBOCAN 2008. Int J Cancer 15: 2893-2917, 2010.

2 Pox C, Aretz S, Bischoff C, Graeven U, Hass M, Heußner P, Hohenberger W, Holstege A, Hübner J, Kolligs F, Kreis M, Lux P, Ockenga J, Porschen R, Post S, Rahner N, Reinacher-Schick A, Fiemann JF, Sauer R, Sieg A, Scheppach W, Schmitt W, Schmoll HJ, Schulmann K, Tannapfel A and Schmiegel W: S3Leitlinie Kolorektales Karzinom Version 1.0 - Juni 2013 S3Guideline Colorectal Cancer Version 1.0. Z Gastroenterol 51: 753-854, 2013.

3 Rougier P, Van Cutsem E, Bajetta E, Niederle N, Possinger K, Labianca R, Navarro M, Morant R, Bleiberg H, Wils J, Awad L, Herait $\mathrm{P}$ and Jacques $\mathrm{C}$ : Randomised trial of irinotecan versus fluorouracil by continuous infusion after fluorouracil failure in patients with metastatic colorectal cancer. Lancet 352: 14071412, 1998.

4 Cunningham D, Pyrhönen S, James RD, Punt CJA, Hickish TF, Heikkila R, Johannesen TB, Starkhammer H, Topham CA, Awad $\mathrm{L}$, Jacques $\mathrm{C}$ and Herait P: Randomised trial of irinotecan plus supportive care versus supportive care alone after fluorouracil failure for patients with metastatic colorectal cancer. Lancet 352: 1413-1418, 1998.

5 Fuchs CS, Moore MR, Harker G, Villa L, Rinaldi D and Hecht $\mathrm{R}$ : Phase III comparison of two irinotecan dosing regimens in second-line therapy of metastatic colorectal cancer. JCO 21: 807-814, 2003.

6 Graeven U, Arnold D, Reinacher-Schick A, Heuer T, Nusch A, Porschen R and Schmiegel W: A Randomised phase II study of irinotecan in combination with 5-FU/FA compared with irinotecan alone as second-line treatment of patients with metastatic colorectal carcinoma. Onkologie 30: 169-174, 2007.

7 Tournigand C, André T, Achille E, Lledo G, Flesh M, MeryMignard D, Quinaux E, Couteau C, Buyse M, Ganem G, Landi $\mathrm{B}$, Colin P, Louvet C and de Gramont A: FOLFIRI followed by FOLFOX6 or the reverse sequence in advanced colorectal cancer: a randomized GERCOR study. JCO 22: 229-237, 2004.

8 Van Cutsem E, Tabernero J, Lakomy R, Prenen H, Prausová J, Maraculla T, Ruff P, van Hazel GA, Moiseyenko V, Ferry D, McKendrick J, Polikoff J, Tellier A, Castan R and Allegra C: Addition of aflibercept to fluorouracil, leucovorin, and irinotecan improves survival in a phase III randomized trial in patients with metastatic colorectal cancer previously treated with an oxaliplatin-based regimen. JCO 30: 3499-3506, 2012.

9 Tabernero J, Yoshino T, Cohn AL, Obermannova R, Bodoky G, Carcia-Carbonero R, Ciuleanu TE, Portnoy DC, Van Cutsem E, Grothey A, Prausová J, Garcia-Alfonso P, Yamazaki K, Clingan PR, Lonardi S, Kim TW, Simms L, Chang SC and Nasroulah F: Ramucirumab versus placebo in combination with second-line FOLFIRI in patients with metastatic colorectal carcinoma that progressed during or after first-line therapy with bevacizumab, oxaliplatin, and a fluoropyrimidine (RAISE): a randomised, double-blind, multicentre, phase 3 study. Lancet Oncol 5: 499$508,2015$.
10 Peeters M, Price TJ, Cervantes A, Sobrero AF, Ducreux M, Hotko Y, André T, Chan E, Lordick F, Punt CJ, Strickland AH, Wilson G, Ciuleanu TE, Roman L, Van Cutsem E, Tian Y and Sidhu R: Final results from a randomized phase 3 study of FLOFIRI \pm panitumumab for second-line treatment of metastatic colorectal cancer. Ann Oncol 25: 107-116, 2014.

11 Köhne C-H, van Cutsem J, Wils J, Bokemeyer C, El-Serafi M, Lutz MP, Lorenz M, Reichardt P, Rückle-Lanz H, Frickhofen N, Fuchs R, Mergenthaler HG, Langenbuch T, Vanhoefer U, Rougier P, Voigtmann R, Müller L, Genicot B, Anak O and Nordlinger B: Phase III study of weekly high-dose infusional fluorouracil plus folinic acid with or without irinotecan in patients with metastatic colorectal cancer: European Organisation for Research and Treatment of Cancer Gastrointestinal Group Study 40986. JCO 23: 4856-4865, 2005.

12 Fischer von Weikersthal L, Schalhorn A, Stauch M, Quietzsch D, Maubach PA, Lambertz H, Oruzio D, Schlag R, WeigangKöhler K, Vehling-Kaiser U, Schulze M, Truckenbrodt J, Goebeler M, Mittermüller J, Bosse D, Szukics B, Grundeis M, Zwingers T, Giessen C and Heinemann V: Phase III trial of irinotecan plus infusional 5-fluorouracil/folinic acid versus irinotecan plus oxaliplatin as first-line treatment of advanced colorectal cancer. EJC 47: 206-214, 2011.

13 Douillard JY, Cunningham D, Roth AD, Navarro M, James RD, Karasek P, Jandik P, Iveson T, Carmichael J, Alakl M, Gruia G, Awad L and Rougier P: Irinotecan combined with fluorouracil compared with fluorouracil alone as first-line treatment for metastatic colorectal cancer: a multicentre randomised trial. Lancet 355: 1041-1047, 2000.

14 Stickel F, Jüngert B, Brueckl V, Schirner I, Brueckl WM, Männlein G, Hegewald J, Mühldorfer S, Bittorf B, Hohenberger W, Hahn EG and Wein A: Weekly high-dose 5-fluourouracil as 24-h infusion and folinic acid (AIO) plus irinotecan as secondand third-line treatment in patients with colorectal cancer pretreated with AIO plus oxaliplatin. Anticancer Drugs 9: 745-749, 2003.

15 Wein A, Boxberger F, Siebler J, Wolff K, Ostermeier N, Busse D, Männlein G, Hohenberger W, Neurath MF and Hofheinz R: Efficacy and toxicity of second-line AIO plus irinotecan (IRI) after pre-treatment with AIO plus oxaliplatin (L-OHP) in the sequential therapy of metastatic colorectal cancer (CRC). JCO Abstract No. 3561, 2013.

16 Thrasse P, Arbuck SG, Eisenhauer EA, Wanders J, Kaplan RS, Rubinstein L, Verweij J, Van Glabbeke M, van Oosterom AT, Christian MC and Gwyther SG: New guidelines to evaluate the response to treatment in solid tumors. European Organization for Research and Treatment of Cancer, National Cancer Institute of the United States, National Cancer Institute of Canada. J Natl Cancer Inst 92: 205-216, 2000.

17 DCTD N, NIH, DHHS: Cancer therapy Evaluation Program Common Toxicity Criteria, version 2.0, 1999.

18 Mace AE, Robert E and Krieger E: Sample-size determination. publishing company, Huntington, New York 107-110, 1974.

19 Greenwood M: the natural duration of cancer. Reports on Public Helath and Medical Subjects, 33. London, Her Majesty's Stationary Office, 1926.

20 Grothey A, Sargent D, Goldberg RM and Schmoll HJ: Survival of patients with advanced colorectal cancer improves with the availability of fluorouracil-leucovorin, irinotecan, and oxaliplatin in the course of treatment. JCO 22: 1209-1214, 2004. 
21 Grothey A and Sargent D: Overall Survival of Patients With Advanced Colorectal Cancer Correlates With Availability of Fluorouracil, Irinotecan, and Oxaliplatin Regardless of Whether Doublet or Single-Agent Therapy Is Used First Line. JCO 23: 9441-9442, 2005.

22 Wein A, Emmert M, Merkel S, Harich H-D, Siebler J, Thiemann R, Lamberti C, Göttler B, Fries S, Kiani A, Schlag R, Grüner M, Steinbild S, Eberl S, Pohl-Dernick K, Dörje F, Horbach T, Schöffski O, Neurath MF and Hohenberger W: Palliative treatment of colorectal cancer with secondary metastasis resection in Germany - Impact of the multidisciplinary treatment approach on prognosis and cost: The Northern Bavaria IVOPAK I Project. Oncol 88: 103-121, 2015.

23 Bennouna J, Sastre J, Arnold D, Osterlund P, Greil R, Van Cutsem E, von Moos R, Viéitez JM, Bouché O, Borg C, Steffens CC, Alonso-Orduna V, Schlichting C, Reyes-Rivera I, Bendahmane B, André $\mathrm{T}$ and Kubicka S: Continuation of bevacizumab after first progression in metastatic colorectal cancer (ML18147): a randomised phase 3 trial. Lancet Oncol 14: 29-37, 2013.

24 Muro K, Boku N, Shimada Y, Tsuji A, Sameshima S, Baba H, Satoh T, Denda T, Ina K, Nishina T, Yamaguchi K, Takiuchi H, Esaki T, Tokunaga S, Kuwano H, Komatsu Y, Watanabe M, Hyodo I, Morita S and Sugihara K: Irinotecan plus S-1 (IRIS) versus fluorouracil and folinic acid plus irinotecan (FOLFIRI) as second-line chemotherapy for metastatic colorectal cancer: a randomised phase 2/3 non-inferiority study (FIRIS study). Lancet Oncol 11: 853-860, 2010.

25 Wein A, Siebler J, Görtz R, Wolff K, Ostermeier N, Busse D, Kremer AE, Koch F, Hagel A, Farnbacher M, Kammerer FJ, Neurath MF and Gruetzmann R: Successful multidisciplinary treatment with secondary metastatic liver resection after downsizing by palliative second-line treatment of colorectal cancer (CRC) - a curative option. Case Rep Oncol 9: 379-386, 2016.
26 Brouquet A, Overman MJ, Kopetz S, Maru DM, Loyer EM, Andreou A, Cooper A, Curley SA, Garrett CR, Abdalla EK and Vauthey JN: Is Resection of Colorectal Liver Metastases After a Second-Line Chemotherapy Regimen Justified? Cancer 117: 4484-4492, 2011.

27 Cunningham D, Humblet Y, Siena S, Khayat D, Bleiberg H, Santoro A, Bets D, Mueser M, Harstrick A, Verslype C, Chau I and Van Cutsem E: Cetuximab Monotherapy and Cetuximab plus Irinotecan in Irinotecan-Refractory Metastatic Colorectal Cancer. N Engl J Med 351: 337-345, 2004.

28 Bidard FC, Tournigand C, André T, Mabro M, Figer A, Cervantes A, Lledo G, Bengrine-Lefevre L, Maindrault-Goebel F, Louvet $\mathrm{C}$ and de Gramont A: Efficacy of FOLFIRI3 (irinotecan D1,D3 combined with LV5-FU) or other irinotecanbased regimens in oxaliplatin-pretreated metastatic colorectal cancer in the GERCOR OPTIMOX1 study. Ann Oncol 20: 10421047, 2009.

29 Giessen C, Graeven U, Laubender RP, Modest DP, Schulz C, Porschen R, Schmiegel W, Reinacher-Schick A, HegewischBecker S, Stintzing S and Heinemann V: Prognostic factors for 60-days mortality in first-line treatment of metastatic colorectal cancer (mCRC): indiviual patient analysis of four randomised, controlled trials by the AIO colorectal cancer study group. Ann Oncol 24: 3051-3055, 2013.

Received May 10, 2017

Revised May 31, 2017

Accepted June 2, 2017 